\title{
PENSAMIENTO ESCOTISTA EN LA ESPAÑA MEDIEVAL (SIGLOS XIV-XV)
}

\author{
Vicente Muñiz Rodríguez \\ Universidad Pontificia de Salamanca
}

\section{RESUMEN}

Durante los siglos XIV-XVI, las doctrinas filosóficas de. Duns Escoto adquirieron gran florecimiento en la península ibérica, especialmente en el reino de Aragón. Pero, no todos los escotistas españoles fueron fieles intérpretes del pensamiento de Duns Escoto, como sucedió con Antonio Andrés, la figura más representativa del primer escotismo español.

\section{ABSTRACT.}

Scot's thought in he Spanish Medieval Philosophy. Duns Scot's philosophical doctrine got a great development in the Iberian Peninsula, especially in the Kingdom og Aragon, during 14th-16th centuries. But not all the Spanish Scotists were faithfull interpreters of Scot's thought, as it happened to Antonio Andrés, the most representative philosopher of the Spanish Scotism.

Las doctrinas filosófico-teológicas del Beato Juan Duns Escoto adquirieron durante los siglos XIV y XV, especialmente en el XIV, un gran florecimiento en la península ibérica. De manera más cncreta y particular, en el antiguo reino de Aragón. Este fenómeno del pensamiento escotista nos retrotrae al problema del cuándo y cómo advienen y pasan dichas doctrinas de los «studia» 0 casas de estudio conventuales y provinciales (particulares) a los Estudios Generales y Universidades del medioevo español. Igualmente nos retrotrae también a las fuentes de que disponemos para determinar sus contenidos y describir la geografía desde la que éstos se irradiaron por toda la Península. En efecto, la escasez de subsidios documentales y literarios dificulta precisar en su cuadro exacto una panorámica del escotismo en España. Faltan estudios completos sobre la tradición manuscrita de los autores franciscanos de este periodo. Falta también conocer con detalle las cátedras regentadas, fuera de la Orden, por los franciscanos seguidores de Escoto y la lista de maestros y lectores de teología y filosofía, así como la historia de las casas de estudio conventuales minoritas. Carecemos, sobre todo, de ediciones 
críticas, excepción hecha de las Questiones disputatae et de Quodlibet de Gonzalo Hispano y la del Comentario al I de las Sentencias de Pedro de Navarra, llevadas a cabo por L. Amorós y P. Sagüés respectivamente.

Teniendo en cuenta esta situación, propósito de este estudio, después de un breve apunte en torno al origen y desarrollo doctrinal escotista en España, es el de exponer, en sus líneas maestras, la sucesión de figuras más célebres y los escritos en que vierten las enseñanzas de su Maestro. Para ello, el estudio ha sido estructurado en tres partes. la primera atiende al nacimiento de la Orden Franciscana en España y a su relación con los estudios, en los que va cobrar vigencia la escuela escotista. La segunda trata de dar cuenta de los autores más relevantes en la génesis, desarrollo, consolidación y florecimiento de dicha escuela dentro del conjunto de orientaciones filosófico-teológicas que predominaban en aquella época. En efecto, hubo en la península ibérica una escuela fiel al Doctor Sutil, opero no de manera incondicionada, ya que muchas cuestiones se aparta de las enseñanzas del Maestro. En ese sentido, como figura señera no solamente por su influjo en el escotismo posterior sino también por su fidelidad-infidelidad a Escoto, en la tercera parte, le dedicamos un apartado especial al minorita Antonio Andrés.

\section{INICIOS DE LA ORDEN FRANCISCANA EN ESPAÑA Y LOS ESTUDIOS}

Los inicios de la Orden Franciscana en la península ibérica, por tradición y ciertos datos históricos, relación inseparable con el viaje que, en vida, hizo su fundador san Francisco de Asís a Santiago de Compostela. En el año 1219, según el autor de la Crónica de los XXIV Generales, se celebró en la Porciúncula bajo la presidencia del mismo san Francisco un Capítulo General, en el que se nombró a Fr. Juan Parente Ministro Provincial de España. Así fue cómo este franciscano, junto a cien religiosos más, cuyos nombres son desconocidos en su mayor parte, comenzó a construir la historia de su Orden en la península ibérica. En menos de un cuarto de siglo las comunidades franciscanas españolas tuvieron tan rápido incremento que se delimita la península ibérica como «Provincia de España» y se desmembra ulteriormente en tres provincias: Galicia, Castilla y Aragón. ${ }^{2}$ La aparición de Juan Duns Escoto en el escenario intelectual de Europa coincide con la panorámica descrita, respecto de España. Y conviene poner de relieve este hecho, porque español fue, procedente de la Provincia de Galicia, Fr. Gonzalo Hispano, Primero, Rector del estudio General franciscano de París, Profesor de

1 Vázquez, I., "Aurea aetas scotismi. (Saeculi XVI-XVIII)» en De doctrina Ioannis Dunns Scoti. Acta Congressus Scotistici Internationalis Oxonii et Edimburgi 11-17 sept. 1966 celebrati, vol. IV. Romae 1968. 191194: Carreras Artau, T. y J., Historia de la Filosofía española. Filosofía cristiana de los siglos XIII al XV. t. II. Madrid, 1943, 459-471. Amorós, L., Fr: Gonsalli Hispani OFM quaestiones disputatae et de Quodlibet, Ad Claras Acquas 1935 y Sagüés, P., El maestro Pedro de Nararra OFM (m. 1347), "doctor fundatus» y su comentario sobre el libro I de las Sentencias, Madrid 1966.

2 López, A., La Prorincia de España de los Frailes Menores. Apuntes histórico-críticos sobre los orígenes de la Orden franciscana en España, El eco franciscano, Santiago, 1915. 28-29. 
Teología en su Universidad. Maestro del Doctor Sutil y, después, General de la Orden. Como tal, es quien recomienda a Escoto para su presentación al doctorado en la Sorbona. Según la Carta comendaticia, Fr. Gonzalo Hispano le conocía «por larga experiencia». El mismo Gonzalo Hispano es quien puso, más tarde, a Escoto e relación con tres franciscanos que, luego, serían propagadores del pensamiento escotista en España: el portugués Alvaro Pelayo, el bretón Anfredo Gonter y el aragonés Antonio Andrés. ${ }^{3}$

La labor formativa de los franciscanos se estructuraba, dentro de la división tripartita provincial ibérica, en Estudios Generales y Estudios Particulares. Los primeros eran «generales» tanto por razón de las materias enseñadas -desde la gramática has ta la teología- como por razón del personal docente o discente, que podía acudir a ellos desde cualquiera otra Provincia de la Orden. Ofrecían una superioridad en el nivel de enseñanza, por ser las clases impartidas por Maestros de alta solvencia científica. Los Estudios Particulares, en cambio, eran casas de formación para estudiantes de una sola comunidad o de una sola Provincia de la Orden. El escotismo se consolidó en España, precisamente, por el empuje y buena organización de dichos Estudios. En menor cuantía existían los estudios universitarios, que, por estar incorporados siempre a una universidad vecina, gozaban de la facultad de dar grados. En las provincias franciscanas españolas de Santiago (Galicia), Aragón y Castilla, aunque no se puedan precisar fechas exactas, fueron poco a poco apareciendo Estudios Generales en Teología. Así, en Aragón, centro de Teología (Barcelona, Lérida, Valencia, Mallorca) y uno de Filosofía en Zaragoza. Valladolid, Palencia y Toledo, en la provincia de Castilla, tuvieron sus respectivos Estudios Generales. En la provincia de Santiago (Galicia), sobresalió el famoso colegio de San Francisco, en Salamanca, donde también estuvo como Rector Gonzalo Hispano.

Al crearse la facultad de Teología en la Universidad de Lérida, en 1430, el Estudio General franciscano, ya con largo historial por tener cátedras de teología regentadas por franciscanos en dicha Universidad, se incorporó a la misma. No obstante, en este mismo siglo, la primacía cultural se vio desplazada al convento de San Nicolás de Barcelona. En Galicia y Castilla, sucedía otro tanto con Salamanca que se convertía en el centro de formación filosófico-teológica de mayor prestigio para los franciscanos de dichas provincias, en detrimento de los Estudios Generales de Valladolid y Palencia.

El currículo escolar concluía con la adquisición de los títulos correspondientes a los tres grados de artes, filosofía y teología. La formación solía perfeccionarse y completarse en la Universidad de París, Oxford o Cambridge y, a partir de 1457, hasta en 16 universidades más, entre ellas, la misma Salamanca. ${ }^{+}$

3 Pou, J. M., «Fr. Gonzalo de Valboa, primer General de la orden» en Estudios Franciscanos VI (1911) 171180 y $332-342$.

4 Vázquez. I., «Aportaciones históricas literarias a la Historia del pensamiento medieval español» en Antonianum 47 (1972) 641-684 y «Rutas e hitos del escotismo primitivo en España» en Homo et Mundus. Acta quinto Congressus Scotistici Internationalis, Romae 1984, 419-436. 


\section{ESCOTISTAS MÁS IMPORTANTES DEL MEDIOEVO ESPAÑOL}

Durante las enseñanzas de Escoto en la Gran Bretaña, aparece ya un discípulo aragonés: Miguel de Almenara. También, nos encontramos con algunos españoles que convivieron con Escoto en París y adoptaron su misma postura y la de su Maestro Gonzalo Hispano contra el Rey de Francia, Felipe el Hermoso. Postura que, como es sabido, les obligó a abandonar París $\mathrm{y}$, con ello, su carrera.

Con todo, las figuras más representativas del escotismo español se ubican en el área geográfica del antiguo reino de Aragón y fueron Antonio Andrés (m. 1330) «Doctor Dulcifluus», «Fundatissimus» o también «Scotellus»; Pedro Tomás (m. 1340) «Doctor Strenuus», «Proficuus» 0 «Invencibilis»; Pedro de Atarrabia (m. 1347) «Doctor Fundatus»; el bretón Anfredo Gonter y Guillermo Rubió. Estos dos últimos también en la primera mitad del siglo XIV. Guillermo de Rubió, aunque la tradición le hace discípulo de Juan Duns Escoto, se sabe con toda certeza que lo fue en París del escotista Francisco de Marchia. En el ámbito de la literatura política de este mismo siglo, nombres ilustres, considerados discípulos de Escoto, fueron Alvaro Pelayo, en la Provincia de Galicia y el minorita gerundense Francisco de Eiximenis. Estas figuras eclipsan otras más modestas y de segunda fila, como Bernardo de Dios, Guillermo Gorris, Pedro de Castrovol o Juan Vidal. Este último, quizá más conocido que el anterior, por su famosa polémica marianista contra Juan de Monzón. También autores franciscanos, pero escotistas, fueron Francisco Vidal de Noya y Joannes Catalanus.

Característica primera de todos estos autores es la de considerarse a sí mismos seguidores de Escoto. Unos, por haber sido durante su estancia en París compañeros suyos de estudio; otros, por haber sido discípulos y otros, por conocer directamente su obra, cuando todavía estaba en el ambiente su recuerdo. Así, sabemos que Gonzalo Hispano, primer general francisco español que fue Regente del Estudio de París y quien presentó al doctorado en Teología a Escoto y puso -según más arriba se ha indicado- en contacto con éste a Anfredo Gonter y a Alvaro Pelayo que, junto a Antonio Andrés, fueron discípulos directos suyos. Parece que Pedro de Atarrabia estudió en París al poco tiempo de haberse marchado Escoto y, por tanto, cuando todavía las enseñanzas impartidas por el Doctor Sutil se conservaban en apuntes y manuscritos de los que fueron sus oyentes más inmediatos. Por otro lado, Pedro Tomás muestra conocer con claridad los textos directamente escritos por Escoto de los textos ya manipulados por sus discípulos. ${ }^{5}$

Segunda característica es la profesión que todos hacen de seguir las doctrinas del Maestro, aunque, luego, en casos concretos opongan su propia opinión o le interpreten de manera parti-

5 Como ejemplos de este conocimiento de Pedro Tomás respecto a Escoto, pueden aducir estos dos textos: «Modus ponendi istud, videlicet rationes huiusmodi esse rationes obiectivae intellectus et voluntatis, est iste, innitendo dictis Scoti scriptis de manu sua», Petrus Thomas, Quodlibet pars 1. q. 3 (p. 52-53) y «Tertium est quod dicit (Scotus) in quadam celula ubi loquitur de ista materia, est quod dicit quia differt infinitas deitates seu ipsius essentiae ab infinitate bonitatis», Petrus Thomas, De modis distinctionum q. 8 (Madrid, bibl. nac. ms. 2016, f. 71 v. Véase también Martí de Barcelona, «Fr. Père Tomás (s. XIV), Doctor Strenuus et invencibilis» en Estudis Franciscans 39 (27) 90-103. 
cular. Anfredo Gonter, a este respecto, nos presenta su orientación doctrinal en la cuestión 5 del Prólogo 5, fol. 7 r. del Códice Vaticano lat. 1113 del Comentario al Primer libro de las Sentencias, al manifestar «... a nuestro Hermano, el Venerable Doctor Juan Escoto, a quien sigo en casi todas las cuestiones, en cuanto es posible, porque escuché sus enseñanzas...». Igualmente, Pedro de Atarrabia nos indica que sostiene las doctrinas de Escoto «in pluribus», expresión que, otras veces, sustituye por «in multis». Así, por ejemplo, al tratar de demostrar la existencia de Dios, señala: «El Hermano Juan Escoto, a quien sigo en la mayoría de sus doctrinas, afirma que la existencia de Dios puede ser demostrada; y esto lo que yo también defiendo». En cambio, al referirse al tema de la relación entre Dios y las creaturas, indica: «según este Doctor (Escoto), a quien sigo en muchas cuestiones». De manera parecida, Pedro Tomás declara su orientación doctrinal netamente escotista, cuando afirma: «... porque Escoto, cuya enseñanza sigo de manera habitual...». Guillermo Rubió, formado en el escotismo, tampoco permaneció fiel en todo a las enseñanzas del Maestro. Exacerbado por un criticismo, procedente de Occam, rechazó algunas de las tesis escotistas por demasiado dogmáticas y extremó el rigor en el examen de sus pruebas. Para la depuración de los conceptos de ciencia, experiencia, intuición, entre otros, las ideas de Rubió revisten gran importancia en el escotismo posterio. ${ }^{6}$

Como era común en aquella época, los problemas eran tratados en las aulas a través del comentario al Liber Sententiarum de Pedro Lombardo, de las Quaestiones disputatce o de los asi llamados Quodlibetos. No es de extrañar, por ello, que los escritos de estos seguidores de Escoto que regentaban cátedras, bien en los Estudios Particulares y Generales, de carácter conventual, o en las Universidades fuesen de esta índole. Sin embargo, conviene notar que la obra de Escoto que Pedro Tomás utiliza con mayor frecuencia es la Ordinatio, a la que simplemente denomina Scriptum. Además, atribuye de forma explícita a Escoto el opúsculo Theoremata, tan discutido, por otra parte, en su autenticidad. ${ }^{7}$ De acuerdo con to indicado, tenemos que Guillermo Rubió compuso un gran Comentario al Libro de las Sentencias. Pedro Tomás tiene en su haber, además del Comentario correspondiente a las Sentencias y, por lo menos un quodlibeto, dos obras que fueron muy conocidas más tarde en el siglo XV: De Ente y el De Formalitatibus. Vaticano, Pamplona, Breslau y Barcelona son depositarios de los Códices del Comentario a los cuatro libros de las Sentencias, escrito por Anfredo Gunter de quien conservamos también unas Quaestiones Disputatae de Beatitudine y un opúsculo que se intitula $D e$ Paupaertate Christi. ${ }^{8}$

Con todo, la figura más señera y representativa del escotismo medieval español, no sólo por su gran influencia en la escuela escotista sino también por sus diferencias con el Maestro, es la de Antonio Andrés. Por este motivo, parece obligado dedicarle a él un apartado especial de esta exposición.

6 Saguiés, P.. «Apuntes para la historia del escotismo» en De doctrina loannis Duns Scoti. Acta Congressus Scotistici Internationalis, vol. IV. Romae 1968, 3-19.

7 Sagués, P., o.c., 16.

8 Amorós, L.: «Anfredo Gontero, OFM, discípulo de Escoto y Lector en el Estudio General de Barcelona» en Revista Española de Teología 1 (1940-4l) 545-572. 


\section{ANTONIO ANDRÉS O LA FIDELIDAD QUEBRADA}

Mariano de Florencia, cronista franciscano antiguo, enumera entre los discípulos de Escoto qui maxime profecerunt a Antonio Andrés. Y, haciéndose eco de la opinión común de la época, afirma del mismo que es doctrinae sui magistri Scoti praecipuus defensor. El nombre de «Scotellus» $\mathrm{y}$ «Scotulus» con los que se le conoce en muchas ocasiones, parecen dejar constancia de esta fidelidad a la doctrina y persona de su Maestro y haber merecido que algunas de sus obras figuraran en la edición Vives de las Opera Omnia del Doctor Sutil, como propias de éste. É. Gilson aseguró que la escuela escotista mantuvo con mayor homogeneidad que la tomista respecto a Santo Tomás las posturas defendidas por Escoto. Sin embargo, los estudios modernos no justifican el aserto de É. Gilson, ya que se mueven por un lado en el intento de fijar la autenticidad bibiográfica de las obras de Escoto en relación con las de sus discípulos y, en consecuencia, por otro, en el de fijar también las diferencias doctrinales de éstos con las del Maestro, que parecen no ser pocas. Tal sucede, al menos, con Antonio Andrés. ${ }^{9}$

\subsection{Problema de la autenticidad bibliográfica}

Los escritos de Antonio Andrés son numerosos y variados, Lo testifican la multiplicidad de manuscritos y de ediciones que de los mismos se conservan. El malogrado P. Martí, en el artículo «Fra Antoni Andreu, O. M., Doctor Dulcifluus», publicado en la revista Criterion V (1929) 321-346, da un elenco no totalmente completo de ellos. Desde entonces no ha aparecido ninguna nueva bibliografía monográfica del minorita aragonés. Han visto la luz pública, sin embargo, valiosos catálogos de manuscritos e incunables en que se da cuenta de los pertenecientes a nuestro autor. Ciñéndonos a estos veinticinco últimos años, son importantes en el sentido indicado:

- En Inglaterra: R. B. Mynors publica Catalogue of the Manuscripts of Balliol College Oxford (Oxford 1963). En él, aparecen las Quaestiones Metaphysicae de A. Andrés en el f. $195 \mathrm{v}-250$.

- En España: dentro del Repertorio de Historia de las Ciencias Eclesiásticas de España, t. 2 (Salamanca 1971) 439-440, se cita un manuscrito de nuestro franciscano que se compulsa con la edición de Venecia de 1508 y que perteneció al antiguo Colegio Mayor de San Bartolomé de Salamanca.

- En Holanda: un estudio en colaboración de varios autores, titulado Bio-bibliografia franciscana neerlandica ante saeculum XVI (Nieuwkoop 1974) nos presenta la relación de todos los incunables franciscanos anteriores al siglo XVI. Entre ellos, como es obvio, se encuentran los de Antonio Andrés.

- En Italia: L. Moranti ha reconstruido el catálogo de todas las obras del cinquecento, conservadas en la universidad de Urbino, entre las que abundan las pertenecientes a escritores franciscanos: Nuestro autor aragonés se ubica allí con dos obras. En esta

9 Marianus de Florencia: «Compendium chronicarum Fratrum Minorum» en Archivum Franciscanum Historicum 2 (19.09) 631-632. 
misma línea L. Marchini saca a la luz pública el catálogo de incunables de la biblioteca de Berio, en Génova, en el que se hallan ejemplares de la Metafísica de Antonio Andrés en su edición de Venecia de 1491. Y, por último, C. Piana y A. Fioravanti utilizan obras manuscritas inéditas -más de 60- tratando el problema del alma y sus potencias en Escoto y sus inmediatos discípulos. ${ }^{10}$

Si el P. Martí no ha recibido contribuciones de importancia y continúa todavía siendo punto bibliográfico de referencia válido y seguro, no así sus apreciaciones críticas respecto a la fidelidad a Escoto del minorita Antonio Andrés.

\subsection{Fidelidad e infidelidad de A. Andrés a Escoto}

La doctrina de Antonio Andrés, prescindiendo de las historias de la filosofía, no ha sido nunca tratada de modo sistemático y global en una investigación seria y minuciosa. Se la presenta más bien, dentro del desarrollo y evolución de temas concretos, muy propios y específicos del escotismo. Así, por ejemplo, la Inmaculada y la Anunciación de la Virgen es estudiada por M. E. Gösman; V. Detloff lo hace con la doctrina de la aceptación divina, y De Voogth en los puntos que tiene de connivencia con la Suma inédita de Gerardo de Boloña. ${ }^{1}$

De mayor importancia son los de carácter filosófico. P. Scarpin expone la metafísica escotista en Padua desde el siglo XV hasta el XVII, dedicando un lugar privilegiado al «Doctor Dulcifluus». K. Prantl, en su conocida obra de Lógica, expone las doctrinas de Antonio Andrés en este campo. Pero es particularmente C. Berubé quien aporta más datos sobre la independencia de opinión de Antonio Andrés respecto a Escoto en el problema del conocimiento de lo individual. Problema que en el sistema del pensador escocés es de capital relevancia.

Según C. Berubé, Antonio Andrés es el pionero y el promotor de la doctrina del conocimiento del universal sin especie universal inteligible. Fundado sobre un conocimiento directo del singular sin intuición intelectual. Tal doctrina se distancia del pensamiento personal de Duns Escoto, aunque se le atribuya por los escotistas de primera hora, haciendo alarde de su fidelidad al Maestro. Esto motiva en C. Berubé una búsqueda de los textos fundamentales a partir de los que se afirma y desarrolla tal doctrina. En esta búsqueda llega a Antonio Andrés del que se encuentra en la Biblioteca central de los Capuchinos de Roma un ejemplar de la edición de 1523 y que Martí cita en p. 338 del estudio señalado anteriormente. El ejemplar hallado se intitula Quaestiones super libros Metaphysicae. Manifiestamente se trata en sus nueve primeros libros de un resumen de las Quaestiones super lib. Metaph. de Duns Escoto. Los libros X-XII, en cambio, están elaborados sobre los textos de Escoto, agrupados con arte y habilidad tal que prueban y afirman opiniones y posturas diversas de las defendidas personalmente por el Doctor Sutil. C. Berubé, por tanto, prueba sin lugar a dudas la existencia de dos obras diferentes. Mientras una no tuvo mayor incidencia en el desarrollo del escotismo, aun-

10 Muñiz Rodríguez, V., «Antonio Andrés. La edición veneciana de su Logica Vetus de 1509» en Curadernos Salmantinos de Filosofía VI (1979) 272-282.

11 Gösman, M.. Die Verkïndigung an Maria in dogmatischen Verständnis des Mittelalters, München 1957 y Dettloff, W., Die Entricklung det Akzeptations und Verdienslehre ion Duns Scotus bis Luther: Mit bensoderer Beriicksichtigung der Franziskanertheologen, Münster, Westfalen 1963. 
que sea del mismo Escoto, no así la otra, de la cual nos habla toda la tradición exegética como perteneciente a Antonio Andrés. Es en ésta donde so pretexto de fidelidad al maestro, el minorita aragonés quebranta su proclamada fidelidad y pone en este camino al escotismo posterior. ${ }^{12}$

En esta última línea, en los últimos años, Angel d'Ors ha investigado el Scriptum super Librum perihermeneias de Antonio Andrés, a propósito de la cuestión Utrum Nomen significet rem vel passionem in anima. Con tal fin, coteja de manera detallada los problemas planteados por el Scriptum primi et secundi libri Perihermeneias cum notabilibus et dubiis et quaestionibus, contenido en el manuscrito 6 de la Catedral de Pamplona, perteneciente a Antonio Andrés y los del In librum Perihermenias quaestiones de Duns Escoto. Su conclusión pone de manifiesto cómo, bajo la apariencia de fidelidad literal a las doctrinas de Escoto, Antonio Andrés defiende una doctrina radicalmente diversa. Dicha doctrina influirá en la orientación posterior escotista. No sucede lo mismo, según siempre Angel d'Ors, con la cuestión 11 del manuscrito aducido: Utrum propositio de futuro sit determinate vera vel falsa. En ella, Antonio Andrés realiza una mera organización de las cuestiones de Escoto, ligeramente simplificadas, en la que a la fidelidad literal a los textos de Escoto corresponde también una fidelidad doctrinal. ${ }^{13}$

Después de esta resumida exposición, podemos concluir que fidelidad e infidelidad son características muy específicas de la escuela escotista medieval española. Y es en esta línea en la que se mueve la investigación actual: mostrar la autenticidad de las obras atribuidas a los discípulos inmediatos de Juan Duns Escoto, para poder, por tanto, indicar las diferencias doctrinales existentes entre el escotismo y el pensamiento personal propio del Doctor Sutil.

\author{
Vicente Muñiz Rodríguez \\ Padres Capuchinos \\ Ramón y Cajal, 5-7 \\ E-37007 SALAMANCA
}

12 Berubé: C., «Antoine André, témoin et interprete de Scot» en Antonianum 54 (1979) 386-446.

13 D Ors: A., «Utrum nomen significet rem vel passionem in anima (Antonio Andrés y Juan Duns Escoto)». Contribución al Xth European Symposium on Mediaeval Logic and Semantics, Nimega 1992. También d'Ors, A.: en el III Simposio de Historia de la Lógica, celebrado en Pamplona entre los días 3. y 5 de mayo, presentó otro estudio sobre la cuestión: «Utrum propositio de futuro sit determinate vera vel falsa (Antonio Andrés y Juan Duns Escoto)», y que está en vías de publicación. 